\title{
RELACIONAMENTO, COOPERAÇÃO E GOVERNANÇA EM ARRANJOS PRODUTIVOS LOCAIS: O CASO DO APL DE MADEIRA E MÓVEIS DO ESTADO DE RONDÔNIA
}

\author{
Marcia Cristina Teixeira \\ marcia.foganca@gmail.com \\ Centro Universitário Luterano de Ji-Paraná - RO / Brasil \\ Rivanda Meira Teixeira \\ rivandateixeira@terra.com.br \\ Universidade Federal de Sergipe - SE / Brasil
}

Recebido em 15/03/2008

Aprovado em 23/03/2010

Disponibilizado em 01/04/2011

Avaliado pelo sistema double blind review

Revista Eletrônica de Administração

Editor: Luís Felipe Nascimento

ISSN 1413-2311 (versão on-line)

Editada pela Escola de Administração da Universidade Federal do Rio Grande do Sul.

Periodicidade: Quadrimestral

Sistema requerido: Adobe Acrobat Reader.

\section{INTRODUÇÃO}

A análise da cooperação entre empresas tem demandado crescente interesse nas pesquisas no campo organizacional. A abordagem de redes é, de acordo com Hatch (1997), uma maneira de ver as organizações, não como ilhas isoladas e independentes umas das outras, mas como conjunto inserido em contexto econômico, social e político. Dentro desse contexto, a abordagem é relacional, pois se preocupa em ver as organizações sempre em relação às outras organizações. Fazer uma análise de maneira individual não encontra mais sentido no momento atual, pois cada vez mais os limites da organização se estendem além das fronteiras físicas e se confundem com o ambiente. As parcerias, os contatos formais e informais são, afirmam Dyer e Singh (1998), partes da organização e podem ser vistos como seus recursos organizacionais, apesar de ultrapassarem seus limites físicos. A configuração em rede consiste, então, em uma forma eficaz para as empresas alcançarem competitividade nos mercados por meio de um complexo ordenamento de relacionamentos nos quais as firmas estabelecem inter-relações.

REAd - Edição 68, Volume 17, Nº 1, jan/abr 2011 - p. 237-269 
Uma das formas de configuração em rede mais destacadas é o arranjo produtivo local (APL), que vem ganhando importância não somente pela possibilidade de geração de novos empregos, crescimento econômico, aumento de exportações e desenvolvimento tecnológico, como também pela atenção que vem recebendo de vários órgãos públicos e instituições privadas (SUZIGAN; FURTADO; GARCIA, 2004).

O presente estudo propõe-se a contribuir com a compreensão do tema por meio da análise do papel dos agentes econômicos e institucionais que atuam no arranjo produtivo local (APL) de madeira e móveis do Estado de Rondônia. Pretende, além de identificar quem são eles, analisar como esses atores se relacionam entre si e com os agentes institucionais presentes nesse arranjo. Especificamente o estudo objetiva verificar como ocorreu o processo de formação do APL, quais os agentes econômicos e institucionais envolvidos, as motivações dos empresários para integrar o APL, as vantagens e desvantagens dessa participação, as formas de cooperação e de governança, o nível de formalidade ou informalidade, o tipo de estratégia e, finalmente, coletar sugestões acerca das principais dificuldades.

Uma análise dos relacionamentos entre esses agentes pode ajudar na compreensão dos determinantes e da natureza inseridos nas relações interorganizacionais, que essas empresas utilizam, de maneira formal ou informal. Inicialmente será apresentada revisão teórica sobre redes organizacionais, sobre arranjos produtivos locais, fatores de cooperação interorganizacionais e governança; a seguir, a metodologia do estudo, finalizando com os principais resultados e as considerações finais.

\section{REDES INTERORGANIZACIONAIS}

Apesar da crescente importância da pesquisa e prática de redes organizacionais, não há consenso em como descrever, explicar e prescrever redes como forma organizacional. A partir de uma análise na literatura, pode-se identificar diferentes definições. Para Jarillo (1988), rede é um modo de organização, baseado na coordenação das atividades econômicas entre atores para o alcance de objetivos estratégicos comuns. Miles e Snow (1992) a descrevem como um padrão de cooperação que tanto pode ser intra ou interfirmas.

Lopes e Moraes (2000) afirmam que o termo rede designa acordos de cooperação econômica entre países, alianças estratégicas entre organizações, interação de grupos, conjunto de contatos desenvolvidos por uma pessoa ao longo da vida e fator de vantagem competitiva para obtenção de um emprego. De acordo com Brown e Butler (1995), tais redes

REAd - Edição 68, Volume 17, No 1, jan/abr 2011 - p. 237-269 
podem ser utilizadas como forma de aliança estratégica para pequenas empresas utilizarem recursos que são externos a eles. Também é uma maneira de empreendedores se assegurarem de informações sobre relacionamentos de mercado que podem ser explorados para garantir futura vantagem competitiva.

Utilizando o termo redes estratégicas, Jarillo (1988, p.32) considera como "arranjos propositais de longa duração entre organizações distintas, mas relacionadas, que se unem para ganhar ou sustentar vantagens competitivas vis-à-vis com seus concorrentes que se encontram fora da rede". Acrescenta o autor que rede é um modo organizacional que pode ser utilizado por administradores ou empreendedores para posicionar suas empresas de modo mais fortemente competitivo.

Jones, Hesterly e Borgatti (1997, p.1) afirmam que redes interfirmas são caracterizadas por um sistema social orgânico ou informal, constituindo uma maneira distinta de coordenação de atividade econômica. Para eles, tal tipo de rede envolve um grupo estruturado, persistente e selecionado de empresas autônomas (ou organizações não remuneradas), engajadas em criar produtos ou serviços baseados em contratos implícitos e informais que possam adaptar-se às mudanças que vierem a ocorrer no ambiente e coordenar e proteger trocas entre elas. Para esses autores, tais empresas são selecionadas, pois não chegam a constituir um setor inteiro, mas podem ser vistas como um subgrupo, pois: (i) há maior freqüência de trocas entre si do que com outras empresas não inseridas na rede; (ii) são persistentes, pois os membros realizam trocas com grande freqüência uns com os outros, criando e recriando as estruturas da rede; (iii) são estruturadas, pois as trocas realizadas não ocorrem uniformemente nem ao acaso; entretanto refletem uma divisão de trabalho e, por fim, os autores utilizam o termo empresas autônomas, para indicar o potencial de cada empresa de ser independente legalmente.

Amato Neto (2000) identificou três variáveis determinantes na formação de redes interfirmas: a diferenciação, a interdependência interfirmas e a flexibilidade. A diferenciação, quando relacionada a uma rede, pode prover a seus participantes todos os seus benefícios inovadores. O mesmo não ocorre, quando se trata de uma empresa isolada, pois a diferenciação, nesse caso, gera elevação em seus custos. Já a interdependência interfirmas pode ser traduzida por um mecanismo que efetivamente prediz a formação de redes e por isso mesmo é adotado como unidade organizacional. A flexibilidade que, de acordo com o autor, deve ser entendida tanto no aspecto inovador e produtivo como no próprio aspecto 
organizacional, é uma das maiores propriedades da rede, pois algumas podem arranjar-se de acordo com suas contingências.

No que tange aos aspectos instrumentais que promovem a constituição da rede, Miles e Snow (1992) destacam que o controle interno da empresa com gerenciamento excessivo pode tornar-se mais caro do que a contratação de serviços externos, cita também a diminuição dos custos de transação e maior capacitação da rede mediante recursos especializados: tais recursos se tornam mais acessíveis quando utilizados em conjunto. Os fatores que dificultam a constituição da rede foram também mencionados por Miles e Snow (1992), que explicam que uma das ameaças é quando um componente da rede perde sua independência com relação a fornecimento de seus produtos.

Paiva Jr. e Barbosa (2001) também mencionam o fator oportunismo como ameaça à constituição de redes interorganizacionais. Os autores citam o oportunismo como sendo um fator predatório, que pode ocorrer quando empresas de portes desiguais e interesses diversos se unem. Tais empresas podem utilizar a rede como forma unilateral de maximização de vantagens. Por sua vez, Williamson (1979) tratou com detalhes a idéia de oportunismo, ao desenvolver a teoria de custos de transação. O autor considera que a empresa contempla diferentes curvas de custo na produção dos diferentes subcomponentes que constituem o produto final. Caso existam algumas empresas que produzam o mesmo produto no mesmo mercado, a priori, o mais eficiente modo de organizar a produção consistiria em uma empresa especializada na produção de cada um dos subcomponentes de um produto. Dessa forma, a empresa especializada apresentaria uma curva decrescente e forneceria às outras empresas, as quais teriam menor custo em relação à produção do que se tivessem que produzir tais produtos elas mesmas.

O autor explica que os custos de transação envolvidos são mais altos do que se a empresa produzir tudo integrada verticalmente. Esses custos são originados pelas transações ineficientes de determinada organização com o seu mercado. Os custos seriam baseados na "racionalidade limitada" do tomador de decisões como a incerteza sobre o futuro, a presença de um pequeno número de agentes para dada transação e a possibilidade de comportamento oportunista por parte de determinados atores econômicos. Para esse autor, a falta de confiança nas relações da empresa com os outros agentes e a possibilidade de comportamento oportunista por parte de alguns empresários representam fatores importantes, senão primordiais, na geração dos custos de transação. 
Jarillo (1988) argumenta que Williamson (1979) não discutiu que os custos de transação podem ser afetados por ações conscientes do empresário, sendo essa uma das principais fundamentações para o conceito de redes estratégicas. A confiança entre os agentes nas inter-relações é um dos fatores que promove a redução dos custos de transação e torna a existência das redes economicamente viáveis, pois é um componente crítico de eficiência e eficácia.

Para este autor a confiança pode ser gerada de forma a criar uma rede. Primeiro, devese escolher cuidadosamente os parceiros com os quais se pretende criar relações econômicas, de preferência com valores e motivações em comum. A segunda variável é a situação intrínseca, pois o empresário não pode esperar por uma "confiança cega"; um comportamento confiável, de acordo com o autor, é gerado quando o empresário mostra que estaria em uma situação pior; se tivesse um comportamento oportunista. Reputação, por exemplo, é um valor que, se quebrado, pode gerar algum tipo de prejuízo. Ênfase em relacionamentos duradouros também é essencial para o desenvolvimento de confiança, porque deixa claro que o relacionamento, por si mesmo, é considerado valioso.

\section{ARRANJOS PRODUTIVOS LOCAIS}

As aglomerações empresariais caracterizam-se principalmente em função da concentração em um determinado espaço geográfico e ocorrem principalmente devido a atrativos regionais que favoreçam em algum aspecto o desenvolvimento econômico empresarial. O fenômeno de múltiplas formas existentes de cooperação entre empresas vem sendo estudado desde o século XIX na Inglaterra por Marshall (1972, apud VALE, 2007, p. 7) que sugeriu que a acumulação e concentração local de conhecimentos, habilidades e know how eram capazes de criar um tipo de atmosfera industrial favorável, gerando benefícios econômicos e difundindo inovação.

Essas reflexões de Marshall foram resgatadas em pelo menos duas diferentes abordagens para o tema da localização: i) os vários trabalhos na área da organização industrial, no qual pode-se incluir não apenas o chamado "Grupo da Califórnia", como também os trabalhos de Porter $(1998,1999)$ e ii) os estudos sobre os distritos industriais, elaborados a partir, inicialmente, de observações de experiências na Itália (VALE, 2007). Um distrito industrial para Marshall (1919, apud AMORIM, 1998, p.28), se compunha de firmas

REAd - Edição 68, Volume 17, No 1, jan/abr 2011 - p. 237-269 
instaladas em um território definido, que exercitam a divisão do trabalho industrial entre si. Refere-se a um conjunto de firmas operando em um mesmo ramo, embora não necessariamente na mesma indústria.

Ao logo das duas últimas décadas diversos autores propõem diferentes tipos e denominações, destacando-se: clusters (AMATO NETO, 2000; PORTER, 1998,1999), distritos industriais (PIORE; SABEL, 1984; COCCO, GAVIÃO E SILVA, 1999), redes (AHUJA, 2000; JARILLO, 1988; CASTELLS, 1999; MILES \& SNOW, 1986 e 1992; OLIVER \& EBERS, 1998; OLIVER, 1990), cooperativismo e associativismo, consórcio (CASAROTTO FILHO e PIRES, 2001) e alianças (DOZ, 1996; BARNIR \& SMITH, 2002).

Vale destacar o pioneirismo de Piore e Sabel (1984) que concordam com a concepção de Marshall quando mencionam que as empresas podem obter vantagens competitivas e se tornam mais eficientes suas operações e estratégias quando atuam de forma associada e conjunta.

Para Sonaglio e Marion Filho (2008) a simples proximidade local, nos termos marshaliano tradicional não é suficiente para explicar o desenvolvimento dos arranjos produtivos locais. A obtenção de eficiência coletiva através de concentração de empresas numa mesma localidade pode ocorrer de três formas: a) pólos: definidos como uma concentração setorial e geográfica de empresas; b) distrito industrial: caracterizado como um agrupamento de empresas, geralmente de pequeno porte, que agrega as vantagens dos pólos à existência de formas implícitas e explicitas de cooperação entre os agentes econômicos locais, proporcionando condições propicias à atividade inovativa; e c) redes de empresas: a atuação em rede reserva a particularidade de que o aprendizado mútuo e a inovação coletiva podem ocorrer mesmo quando não existem grandes agrupamentos de empresas, pois a atuação em rede não está condicionada a uma mesma localidade.

Para Lechner e Dowling (1999) um distrito industrial pode ser definido como um espaço geograficamente limitado onde um grupo de organizações pertencentes à mesma indústria ou a indústrias complementares, além de instituições de apoio. Além disso, destacam que estas empresas costumam ser de pequeno e médio porte. Por sua vez Cocco, Gavião e Silva (1999), mencionam que os distritos industriais são formados de pequenas e médias empresas onde a infra-estrutura física, econômica e social compartilhada, permitem a divisão do trabalho, necessidades e benefícios e criam a condição necessária para a criação e reprodução de um tecido empresarial dinâmico.

Cluster, segundo Amorim (1998) denomina um conjunto numeroso de empresas, em

REAd - Edição 68, Volume 17, No 1, jan/abr 2011 - p. 237-269 
geral pequenas e médias, operando em regime de intensa cooperação, onde cada uma das firmas executa um estágio do processo de produção e se concentram em uma área geográfica definida. Por sua vez Porter (1998 apud CUNHA, 2008, p.2) diz que cluster são concentrações geográficas de organizações interconectadas com grande capacidade competitiva.

Segundo Porter (1999) clusters são grupos, agrupamentos ou aglomerados em concentrações geográficas de empresas de determinado setor de atividade, bem como empresas que possuam algum grau de correlação. Eles se expandem verticalmente tanto em direção aos canais de distribuição quanto aos clientes, como também lateralmente em direção aos fabricantes de produtos complementares e empresas de setores afins. Tais empresas competem em alguns campos e em outros cooperam. O tamanho de um cluster pode variar desde uma pequena região, englobando um ou mais municípios, até uma rede de países vizinhos. Podem assumir diferentes formas, dependendo do seu grau de sofisticação.

Amato Neto (2000) reitera a necessidade de haver ambos os aspectos, setorial e geográfico, concentrados para a existência de um cluster. De acordo com o autor, o que se tem são apenas organizações de produção em setores e geografia dispersas, não formando, portanto, um cluster. $\mathrm{O}$ autor observa ainda que a concentração geográfica e setorial de PME's é sinal evidente da formação de um conglomerado (cluster); entretanto não são suficientes para gerar benefícios diretos para todos os seus membros, benefícios que só podem ser obtidos por meio de um conjunto de fatores facilitadores.

Porter (1999) enfatiza a presença de competitividade em arranjo produtivo. De acordo com o autor, há uma combinação entre cooperação e competição em clusters; esta é facilmente percebida, pois a cooperação é base para o aparecimento de um arranjo e a competição ocorre na busca do ganho de clientes e na sua manutenção. $\mathrm{O}$ autor também enumera os motivos para as empresas cada vez mais se implantarem em aglomerados industriais: acesso a insumos e a pessoal qualificado; acesso à informação; complementaridade; acesso a instituições e a bens públicos e incentivos e mensuração do desempenho.

Schmitz e Musyck (1995, apud ROSA, 2004, p.25) apontam alguns fatores para caracterizar as aglomerações setoriais, são elas: a proximidade geográfica, a especialização setorial, a predominância de pequenas e médias empresas, a colaboração e a competição interorganizacional. Eles destacam também a presença de uma identidade sociocultural que facilita as relações interorganizacionais. Rosa (2004) diferencia aglomerações de empresas e 
clusters, afirmando que a aglomeração de empresas em determinado espaço geográfico em si não implica necessariamente uma cooperação entre elas. A partir do momento em que há essa cooperação, esse aglomerado passa a ser configurado como cluster.

No entanto, como destacam Souza e Bacic (2002), no caso dos aglomerados produtivos setoriais de PMEs, no Brasil e em muitos países, é bem distinta daquela difundida quando se trata dos modelos de distritos italianos (ao menos quando considerados enfaticamente pelo conjunto de seus traços positivos, e não raro "importados" como casosreferência ou padrões).

Argumenta Cunha (2008) que conceitualmente, nas definições expostas pela literatura estrangeira, não existe referência ao termo APL. Esta nomenclatura é uma designação exclusiva dos estudiosos brasileiros, não havendo assim uma tradução ou conceituação específica em outros países.

Coube aos pesquisadores do Redesist, rede de instituições de pesquisa e ensino brasileiras que tem como objetivo a pesquisa sobre Sistemas Produtivos e Inovativos Locais, em 1997 desenvolver o termo em português que traduz o conceito de clusters. Esse termo é o Arranjo Produtivo Local (APL), definido como sendo aglomerações territoriais de agentes econômicos, políticos e sociais - com foco em um conjunto específico de atividades econômicas - que apresentam vínculos mesmo que incipientes (LASTRES e CASSIOLATO 2003). Para esses autores Sistemas Produtivos e Inovativos Locais são aqueles arranjos produtivos em que interdependência, articulação e vínculos consistentes resultam em interação, cooperação e aprendizagem, com potencial de geral o incremento da capacidade inovativa endógena, da competitividade e do desenvolvimento local.

Para Silva, Cardoso e Monteiro (2006) ainda que, no conjunto de estudos e pesquisas desenvolvidas em todo mundo, representem mais um termo e uma definição sobre pólos e distritos industriais e aglomerações econômicas, o conceito de APL toma como premissa básica, a existência de vínculos, mesmo que incipientes, entre os agentes econômicos locais.

Para Teixeira (2008), APLs são aglomerações territoriais de agentes econômicos, políticos e sociais, em que se desenvolve um conjunto específico de atividades produtivas de forma articulada e interdependente. Os arranjos produtivos podem ser constituídos não apenas por aglomerações de empresas de um mesmo setor. Podem abranger, também, fornecedores, clientes, prestadores de serviços, bem como instituições públicas e privadas que os apóiam na formação e capacitação de recursos humanos, na promoção do aprendizado e no financiamento de projetos coletivos. No entanto, as articulações cooperativas adquirem 
variadas formas e densidades, a depender das características históricas, culturais e institucionais que são específicas de cada território.

Vale (2008) destaca que tais sistemas, seriam resultantes da evolução histórica, vinculada a um processo de formação da própria identidade do território onde se inserem. São caracterizados, também, por uma dimensão territorial; por um escopo de diferentes atividades e distintos atores econômicos, políticos e sociais aí presentes; pela presença de conhecimento tácito; por processos de inovação e aprendizagem interativos; pela presença de mecanismos de coordenação das atividades (governança) e por um certo grau de enraizamento (embeddedness) das atividades na comunidade local

Argumenta ainda essa autora que aí surgiu conceito de "arranjos" ou "sistemas produtivos e inovativos locais" (APL ou SPIL), que caracterizam conjuntos de agentes econômicos, políticos e sociais, localizados em um mesmo território, desenvolvendo atividades econômicas correlatas e que apresentam vínculos expressivos de produção, interação, cooperação e aprendizado (VALE, 2007).

Para Sampaio et al. (2008) enquanto os estudos sobre APLs concentram-se em micro e pequenas empresas, os de clusters vislumbram agrupamentos de empresas em uma região com sucesso extraordinário em determinado setor de atividade econômica, na qual há predominância de grandes empresas. Os APLs seriam um estágio anterior aos denominados sistemas produtivos e inovativos locais, os quais compreendem arranjos produtivos em que interdependência, articulação e vínculos consistentes (reflexos do capital social) resultam em interação, cooperação e aprendizagem, com potencial de gerar o incremento da capacidade inovativa endógena, da competitividade e do desenvolvimento local (LASTRES e CASSIOLATO, 2003a, 2003b apud SAMPAIO et al., 2008, p.78).

Estas aglomerações de empresas e instituições, de acordo com Suzigan et al. (2004), têm como característica essencial a capacidade de gerar economias externas, sejam elas incidentais ou deliberadamente criadas, que contribuem para o incremento da competitividade das empresas e, em consequiência, do arranjo produtivo local como um todo. Suzigan et al. (2004) evidenciam que as economias externas estão no centro da discussão sobre os sistemas locais. De acordo com eles, tais economias podem ser incidentais, decorrentes de (i) existência de um vasto contingente de mão-de-obra especializada e com habilidades específicas no sistema local; (ii) presença e atração de um conjunto de fornecedores especializados de matéria-prima, componentes e serviços e (iii) grande disseminação dos 
conhecimentos, habilidades e informações concernentes ao ramo de atividade dos produtores locais.

Entretanto os autores apontam a possibilidade de os agentes locais (empresas e instituições) reforçarem sua capacidade competitiva por meio de ações conjuntas deliberadas, tais como compra de matérias-primas, promoção de cursos de capacitação gerencial e formação profissional, criação de consórcios de exportação, contratação de serviços especializados, estabelecimento de centros tecnológicos de uso coletivo, cooperativas de crédito, entre outros. Schmitz e Nadvi (1999, apud Suzigan et al., 2004), afirmam que a união das economias externas incidentais com as obtidas por meio de ações conjuntas deliberadas resulta na já mencionada eficiência coletiva, principal determinante da capacidade competitiva das empresas locais.

A idéia que emerge com o conceito de eficiência coletiva é a de que externalidades locais não são suficientes para explicar o desenvolvimento de aglomerações de micros e pequenas empresas (MPEs). De acordo com Schmitz (1995), apesar do conceito de economias externas constituir-se num elemento essencial para compreensão das vantagens derivadas da aglomeração de empresas, ele tem um alcance limitado na medida em que abarca somente aqueles ganhos ou perdas resultantes da facilidade de acesso a insumos especializados, mãode-obra e outros fatores incidentais. Dessa forma, o conceito de eficiência coletiva associa os efeitos decorrentes de economias externas com aqueles que emergem a partir da ação deliberada de cooperação entre os atores locais. A noção de eficiência coletiva constitui-se num referencial analítico importante para explicar as diferenças associadas ao desempenho de aglomerações, sustentada pela existência de canais de comercialização e confiança mútua nas relações interorganizacionais. O fator confiança será explicado adiante.

Souza e Mazzali (2008) destacam que para que as pequenas empresas integrantes desses particulares arranjos organizacionais de empresas (referindo-se a aglomerações geográfica de determinados setores) construam vantagens competitivas (relativamente a empresas de fora do arranjo), é necessário que sejam capazes de desenvolver ações conjuntas e coordenadas que permitam obter ganhos e vantagens que seriam inacessíveis a uma pequena unidade individual. Explicam que as características dessa forma de organização coletiva sinergias potenciais, pouca divisão de trabalho por empresa versus significativa divisão de trabalho no interior do distrito, posições pouco rígidas, poder das empresas não muito desigual e baixa hierarquia nas relações entre empresas - garantem grande flexibilidade. A organização "comunal”, além de propiciar eficiência técnica, confere certo poder coletivo de 
manobra, normalmente acessível apenas às grandes empresas, visto que pode ampliar o peso e a voz política das pequenas empresas, inclusive no que diz respeito a demandas ao setor público.

É evidente, afirmam esses autores, que todas essas vantagens podem não ter caráter permanente (como, aliás, qualquer vantagem). Aparentemente, no entanto, esses distritos garantem certa importância em termos de dinamismo, desenvolvimento industrial e situação econômico-financeira das regiões em que se situam. Dessa forma, as pequenas empresas que os integram estão mais protegidas (com relação a pequenas empresas não organizadas em rede) porque, em uma situação de declínio, poderão, ao menos, beneficiar-se de sua posição relevante em termos de desenvolvimento regional. Isso lhes assegura menor grau de incerteza quanto às possibilidades de permanência continuada, talvez com um perfil remodelado.

Porter (1999) destaca o papel do governo no desempenho de um APL. De acordo com o autor, o governo acaba desempenhando um número de papéis na economia, sendo o principal deles gerar estabilidade política e macroeconômica. Também é papel do governo a criação de condições de capacitação geral da microeconomia, podendo, nesse sentido, prover a capacitação educacional da força de trabalho, infra-estrutura física apropriada, informação econômica atualizada e precisa, além do estabelecimento de regras, normas e condutas, enfim, a base fundamental para o desenvolvimento de uma atividade econômica em um país.

Scheffer, Cario e Nicolau (2008) argumentam que os arranjos produtivos locais, bem como as organizações, proporcionam ambientes favoráveis à maior circulação do conhecimento codificado, através do acesso a canais de informação e principalmente dos conteúdos tácitos, por meio de observações diretas e interações face a face. Assim, por estarem inseridas em APLs, as empresas de pequeno porte têm maiores possibilidades de desenvolver diferenciais competitivos importantes, a partir de oportunidades locais de aprendizado.

Maria, Faria e Amorim (2008) destacam ainda que os APLs constituem influente referência para a formulação de políticas de promoção das atividades produtivas e do desenvolvimento local, especialmente quando se trata de micro e pequenas unidades de produção. Argumentam ainda que com efeito, diversos órgãos públicos e organizações não governamentais adotam, hoje, a abordagem de APLs e possuem estratégias de ação voltadas especificamente para fomentar as aglomerações produtivas territoriais. A apreensão de significados relacionados à abordagem de APLs no Brasil, contudo, é ainda incipiente por 
parte de representantes de órgãos públicos, privados e pela sociedade civil, dando ensejo a uma série de equívocos sobre o modus operandi dessas organizações.

De acordo com Lastres e Cassiolato (2005), há uma série de vantagens em se trabalhar com foco em Arranjos Produtivos Locais, dentre elas as principais são: (i) representação de uma unidade de análise que vai além da tradicional visão baseada na organização individual (empresa), setor ou cadeia produtiva, que permite estabelecer uma ponte entre o território e as atividades econômicas; (ii) foco em grupos de agentes (empresas e organizações de P\&D, educação, treinamento, promoção, financiamento etc.) e atividades conexas que caracterizam qualquer sistema produtivo e inovador; (iii) demarcação do espaço, onde ocorre o aprendizado, pois são criadas as capacitações produtivas e inovadores e fluem os conhecimentos tácitos; (iv) representação do nível em que as políticas de promoção do aprendizado, inovação e criação de capacitações podem ser mais efetivas.

\section{COOPERAÇÃO INTERORGANIZACIONAL}

Para Souza e Bacic (2002) o desenvolvimento das relações de cooperação possibilita o acesso a um conjunto de benefícios, inatingível às empresas individuas isoladas: economias de escala, possibilidades de externalização e especialização produtiva, aumento da capacidade de decisão no referente à variáveis estratégicas (a network diminui a incerteza), acesso à mercados maiores, aumento do poder de barganha nas compras, maior capacidade de aprendizado, maiores possibilidades de inovação (dadas a externalização/especialização, as melhores informações de mercado e a melhor potencial de aprendizado), redução de custos em função do desenvolvimento de ações conjuntas, acesso a novas tecnologias, novos materiais e métodos inovadores de produção.

Hushima e Bulgacov (2006) afirmam que compartilhar atividades e recursos por meio das relações e alianças com outras empresas pode acentuar vantagens competitivas, reduzindo custos ou reforçando a diferenciação. Os processos integrados entre as empresas, como serviços, fornecimento e distribuição podem levá-las a obter melhores resultados além do lucro, como: informações, conhecimentos, sinergia e compartilhamento de operações. Para esses autores, a aglomeração de empresas e o aproveitamento das sinergias geradas a partir da cooperação fortalecem as chances de sobrevivência, de crescimento e de competitividade no mercado. A participação dinâmica das pequenas empresas em arranjos auxilia-as no 
enfrentamento das barreiras de entrada no mercado. Muitas políticas governamentais têm até enfatizado e estimulado a formação de arranjos produtivos locais para o desenvolvimento industrial e a geração de inovações. Incluem-se nesses arranjos as produtoras de bens e serviços, as comercializadoras, os consumidores, as organizações públicas ou privadas, as escolas técnicas, as universidades, entre outras.

No que tange à cooperação entre empresas, Lopes e Baldi (2005) afirmam que a confiança tanto é resultado como meio da interação cooperativa, porquanto em um mundo de crescente incerteza e complexidade, é a confiança o mecanismo mais apropriado para controlar a vida organizacional, mais que o poder hierárquico e a supervisão direta, dada à racionalidade limitada dos agentes. Ring e Van de Ven (1992) afirmam haver algum elemento de confiança em todos os tipos de transações realizadas entre empresas. Entretanto, conforme as relações entre as empresas se repetem, há uma tendência para que o grau de confiança aumente. Conforme as transações vão efetivando-se com sucesso e uma das partes percebe que o outro seguiu corretamente as normas de eqüidade, o grau de confiança para transações posteriores irá aumentar (GULATI, 1995).

Gulati (1995) explica que a confiança diminui a apreensão de que uma das partes irá agir de forma oportunística. A idéia de que a confiança interorganizacional aumenta conforme aumentam as interações ocorridas entre os parceiros se dá também porque em cada uma dessas interações os parceiros recebem mais informações uns dos outros. Minimizando o comportamento oportunístico, a confiança diminui os custos de transação de uma relação de troca e provê um mecanismo de controle substituto. A reputação de uma empresa é de extrema importância, pois elas estão insertas em uma densa rede de relações sociais. Devido a isso, a reputação é de extrema importância para relacionamentos futuros.

Lopes e Baldi (2005) colocam alguns motivos que explicam a influência dos laços sociais na formação de um arranjo interorganizacional cooperativo. São eles: a) laços sociais facilitam o fluxo de informações entre atores organizacionais nas trocas de mercado. b) laços sociais podem gerar confiança entre os parceiros, o que reduz os custos de transação decorrentes da realização de contratos detalhados. c) laços sociais representam apoio alternativo, quando as instituições responsáveis pelas regulações de troca não dispõem de credibilidade. d) laços sociais podem agilizar transações de mercado, viabilizando pular etapas de negociação, normalmente presentes em relações mais formais, que envolvem atores desconhecidos. e) negociação baseada em laços sociais pode ser uma situação esperada em países onde o personalismo constitui traço cultural chave.

REAd - Edição 68, Volume 17, No 1, jan/abr 2011 - p. 237-269 


\section{GOVERNANÇA EM REDES INTERORGANIZACIONAIS}

Ao caracterizar redes interorganizacionais faz-se necessário tratar da governança dessa estrutura que envolve diferentes organizações autônomas. O termo governança foi emprestado da teoria dos custos de transação (WILLIANSON, 1985) e indica a estrutura necessária para o gerenciamento de alianças entre organizações. Lastres e Cassiolato (2005, p.12) definem governança como (i) processos de tomada de decisão levando à repartição de poder entre governantes e governados, descentralização da autoridade e das funções de governar e a parceria entre o público e o privado; (ii) gestão das interações, sistemas de regulação e mecanismos de coordenação e negociação entre atores sociais.

Para Lastres e Cassiolato (2005, p.13) "governança pode ser definida genericamente como as diversas maneiras pelas quais indivíduos e organizações, sejam elas públicas ou privadas, gerenciam seus problemas comuns, acomodando interesses conflitantes ou diferenciados e realizando ações cooperativas". Esse conceito pode ser utilizado não só para instituições e regimes formais de coordenação e autoridade, mas também para sistemas informais. Os autores mencionam que, tratando especificamente de arranjos ou sistemas produtivos e inovadores locais, pode-se dizer que governança diz respeito aos diferentes modos de coordenação, intervenção e participação, nos processos de decisão local, dos diferentes agentes, em seus vários níveis, empresas, cidadãos e trabalhadores, organizações não-governamentais, etc.; e das diversas atividades que envolvem a organização dos fluxos de produção e comercialização, assim como o processo de geração, disseminação e uso de conhecimentos.

A governança de redes é cada vez mais utilizada para coordenar o relacionamento interorganizacional caracterizado por mecanismos sociais informais em sistemas produtivos complexos inseridos em ambientes de competitividade e incertezas. E é nesse tipo de relacionamento interorganizacional que Jones, Hesterly e Borgatti (1997) embasam sua Teoria Geral de Governança de Redes. Nessa teoria, que busca integrar a Teoria de Redes Sociais à Teoria de Custos de Transação, os autores traçam uma estrutura que identifica condições para que a governança de redes seja capaz de emergir, como também os mecanismos sociais que permitem a coordenação e proteção das trocas interorganizacionais.

Jones et al. (1997) examinam esses mecanismos sociais que possibilitam a governança de redes. O primeiro mecanismo - acesso restrito - trata do número de participantes de uma 
rede. Quanto menor for esse número, mais fácil será conter o oportunismo. Primeiro, porque com mais interações entre os participantes, mais rápida será a possibilidade de saber sobre o grau de fidedignidade de um membro da rede. Segundo, com um número reduzido de participantes há um rápido ajuste mútuo de objetivos e estratégias, reduzindo o custo de coordenação e os incentivos a um comportamento oportunista. Por fim, a expectativa de haver uma maior freqüência e intensidade nas interações no futuro promove a cooperação, o que leva a diminuição do oportunismo.

O segundo mecanismo mencionado por Jones et al. (1997) trata da macrocultura, que é definida como um sistema de valores e premissas amplamente compartilhadas dentro da rede. A macrocultura envolve tanto os relacionamentos diretos e indiretos dentro da rede, como as fontes institucionais e a cultura nacional na qual a rede está inserida. Quanto mais houver o alinhamento estrutural entre os integrantes da rede, maior será o compartilhamento de valores, premissas e compreensões compartilhadas entre eles, o que pode reduzir os custos de coordenação. Os autores recomendam fomentar a socialização entre os integrantes da rede para difundir normas e valores comuns, o que pode ser feito por meio de jornais do setor, eventos, boletins, entre outros.

O terceiro mecanismo social apontado pelos autores se refere às sanções coletivas no qual membros do grupo punindo outros membros que violam normas, valores e objetivos do grupo, podendo ir de rumores, afastamento, até a expulsão. As sanções coletivas protegem as trocas, pois define e reforça os parâmetros dos comportamentos aceitáveis dentro do grupo demonstrando as conseqüências da violação das normas e valores. Elas também reduzem o comportamento oportunista, reduzindo os custos com monitoramento dentro da rede.

Finalmente, Jones et al. (1997) mencionam a reputação dos integrantes da rede como um mecanismo social. A valorização da reputação dos participantes permite aumentar a confiabilidade nas trocas, pois define se um integrante é confiável e leal o suficiente para a realização de trocas de informações ou projetos em comum.

\section{METODOLOGIA}

A abordagem metodológica utilizada na presente pesquisa foi a qualitativa. De acordo com Creswell (2002), essa abordagem possui algumas vantagens tais como a utilização de múltiplos métodos, interativos e humanísticos, e o fato de possuir visão holística do fenômeno estudado. O nível de pesquisa aqui utilizado foi o exploratório-descritivo. O método de 
pesquisa aplicado foi o estudo de caso único (YIN, 2001) tendo como nível de análise o arranjo produtivo local, e a unidade de análise, os gestores tanto das empresas quanto das instituições envolvidas. A pesquisa teve um corte transversal, pois a coleta de dados foi realizada somente em um ponto no tempo e foi baseada no universo pesquisado naquele determinado momento.

O arranjo produtivo local de madeira e móveis situa-se no Estado de Rondônia, nas cidades de Ariquemes, Ji-Paraná, Cacoal, Pimenta Bueno e Rolim de Moura. A seleção desse APL foi baseada nos seguintes critérios: i) arranjo fomentado pelo Serviço de Apoio às Micro e Pequenas Empresas - SEBRAE; ii) em fase de crescimento ou de consolidação de suas atividades; iii) significativo dentro do estado escolhido; iv) acessibilidade na obtenção de dados secundários do setor e do arranjo, bem como de dados primários.

A coleta de dados foi realizada por meio de observação não participante e entrevistas semi-estruturadas. As entrevistas foram realizadas com os dirigentes das empresas participantes no arranjo. Das 35 empresas participantes do APL mencionado, 24 foram visitadas e seus dirigentes, entrevistados. Dentro do arranjo há uma divisão das empresas pela época em que entraram no APL de madeira e móveis de Rondônia: Grupo 1: Constituído por 09 empresas que participam do grupo há cinco anos. Todos os dirigentes foram entrevistados; Grupo 2: Constituído por 11 empresas que participam do grupo há dois anos. Todos os dirigentes foram entrevistados; Grupo 3: Constituído por 15 empresas, todas localizadas na cidade de Ariquemes, que participam do grupo há um ano. Foram realizadas entrevistas com quatro dirigentes selecionados pelo coordenador do SEBRAE entre os mais destacados. Também foram entrevistados os coordenadores do SEBRAE responsáveis pelo APL de madeira e móveis de Rondônia. Sendo assim, a população pesquisada se dividiu em dois grandes grupos:

- Grupo A: dirigentes das empresas que constituem o arranjo produtivo local;

- Grupo B: representantes da instituição de apoio ao arranjo - SEBRAE.

Os dados secundários foram coletados por meio da análise documental das associações que integram o referido APL, livros, revistas especializadas em móveis e relatórios de pesquisa baseados em trabalhos de campo (fornecidos pelo SEBRAE); enfim, tudo o que foi útil para obter dados confiáveis sobre as categorias de análise em estudo e para verificar a autenticidade das informações obtidas por meio das fontes primárias. Esses dados foram tratados predominantemente de forma qualitativa, já que a técnica de análise a ser utilizada foi a análise documental, com posterior análise qualitativa.

REAd - Edição 68, Volume 17, No 1, jan/abr 2011 - p. 237-269 
Os resultados da pesquisa serão apresentados a seguir, de acordo com os objetivos do estudo: o processo de formação do APL de madeira e móveis de Rondônia, os agentes econômicos e institucionais envolvidos, as motivações dos empresários para integrar o referido APL, as vantagens e desvantagens dessa participação, as formas de cooperação e de governança, o nível de formalidade ou informalidade, a estratégia da APL de madeira e móveis e, finalmente, coletar sugestões as principais dificuldades e sugestões para melhorar o seu funcionamento.

\section{PRINCIPAIS RESULTADOS}

\subsection{O Processo de formação do APL}

O arranjo produtivo local de madeira e móveis do estado de Rondônia teve seu projeto concretizado em fevereiro de 2004. Porém, para uma melhor compreensão do processo evolutivo desse arranjo faz-se necessário analisar o projeto que antecede o APL de madeira e móveis, pois é nele que se inicia todo o seu processo de formação.

Inicialmente houve a criação de uma associação de moveleiros na cidade de Rolim de Moura. Essa associação foi criada em 1999 com o intuito de formar um consórcio de exportação de móveis. O empresário Beto Chagas era o presidente da associação na época e foi ele o responsável por buscar apoio junto aos órgãos competentes para dar início ao projeto do consórcio de exportação. O empresário entrou em contato com o coordenador da área de comércio exterior do SEBRAE de Porto Velho, João Machado. Foi o empresário quem tomou conhecimento de um programa governamental chamado Programa Setorial Integrado (PSI) e o mostrou para o coordenador do SEBRAE, que se encarregou de montar um projeto para enviar a Agência Brasileira de Promoção de Exportações e Investimentos (APEX), que era o órgão que disponibilizava recursos para que pequenas empresas pudessem ser capacitadas para exportação. Isso ocorreu em novembro de 1999.

Em 2000, começou o processo de formação do PSI. O coordenador João Machado tinha o intuito de realizar o projeto não só com o grupo pertencente à associação de Rolim de Moura, mas com grupos de várias localidades do estado e, por isso, fez diversas palestras de sensibilização com empresas dos setores de madeira e móveis explicando em que consistia o programa. Após montar o projeto, voltou a todas as cidades para fechar os grupos. Esse 
projeto teve a duração de três anos e capacitou os empresários por meio de consultorias na área de gestão, processo produtivo, design e qualidade. Paralelamente a essas consultorias, o projeto visava também o mercado externo, e por isso, houve participação das empresas em feiras, primeiramente como visitantes e depois como expositores. A APEX financiou o projeto com um milhão de reais, o SEBRAE com oitocentos mil e os empresários pagariam uma taxa de cento e cinqüenta reais por mês.

Conseguiram fechar grupos apenas nas cidades de Rolim de Moura e Ji-Paraná. O projeto foi aprovado pela APEX e em novembro de 2000 iniciou-se um diagnóstico detalhado para uma radiografia das deficiências dessas empresas. Esse diagnóstico incluía desde a matéria-prima, o transporte, a qualificação de mão-de-obra, a capacitação dos empresários, o acesso a financiamento e análise das deficiências de mercado. Com base nesse processo, o SEBRAE e os consultores começaram a desenvolver as ações que sanassem essas dificuldades.

Essas consultorias eram realizadas primeiramente com palestras para todos os empresários, depois com aconselhamento individual, onde eram constatadas as principais deficiências e depois eram sugeridas alternativas para corrigi-las. Deu-se início também a visitas às principais feiras de móveis do Brasil como a FENAVEN em São Paulo e a MOVELSUL em Bento Gonçalves - RS. Em 2003 começaram a expor nessas feiras. Nesse mesmo ano algumas empresas iniciaram o processo de exportação.

Ao final de 2003, o prazo do convênio com a APEX foi encerrado, assim como o projeto do PSI. O SEBRAE Nacional começou a adotar a metodologia de criação de APLs e o grupo que pertencia ao PSI decidiu continuar com o projeto nessa nova metodologia. $\mathrm{O}$ SEBRAE buscou novamente agregar mais empresas ao projeto, desta vez formando grupos em Cacoal, Pimenta Bueno, Ariquemes, bem como outras novas empresas ao grupo de JiParaná e Rolim de Moura. Atualmente, trinta e cinco empresas integram o arranjo, distribuídas nas cidades: Ariquemes - 15 empresas, Cacoal - 4 empresas, Ji-Paraná - 6 empresas,Pimenta Bueno - 6 empresas, Rolim de Moura - 3 empresas, Santa Luzia D’Oeste 1 empresa.

Os principais objetivos do APL de madeira e móveis de Rondônia são: continuidade na melhoria dos processos de produção das empresas; melhorar a eficiência da gestão empresarial; incorporar design, melhorando e inovando produtos; prospectar e atuar em novos nichos de mercado; ampliar a oferta de matéria-prima, por meio do uso racional da floresta; 
articular políticas públicas de acesso a crédito e fortalecer a cooperação entre as empresas e a sua governança.

\subsection{Os agentes econômicos}

Foi possível observar que todos os empresários que integram o APL de madeira e móveis de Rondônia são do sexo masculino, têm em média 42 anos e, em sua maioria, são oriundos da região sul do país. Com relação ao grau de instrução, grande parte concluiu apenas o ensino fundamental $(40 \%)$ e apenas $18 \%$ concluiu ou está concluindo o ensino superior. No que tange à experiência anterior à abertura do atual negócio, pode-se concluir que se trata de uma profissão herdada da família, pois $48 \%$ dos empresários aprenderam a ser marceneiros com os pais. É também por influência da família que a maioria (31\%) decidiu abrir seu atual negócio.

Com relação às organizações, elas têm onze funcionários, produzem móveis para casa e instalações comerciais e estão no mercado, em média, há catorze anos. Quando se trata do tempo dessas empresas no APL de madeira e móveis de Rondônia, foi possível perceber que elas entraram em três períodos diferentes, formando três subgrupos. Nove empresas entraram em 2000, com o início do PSI; doze empresas aderiram ao grupo com o início do referido APL, no início de 2004 e quinze empresas entraram há um ano, no início de 2005.

Foi possível constatar também que grande parte dos empresários (48\%) tomou conhecimento do projeto por meio do SEBRAE, em palestras ou visitas às suas empresas. Essa prática ocorre para sensibilizar empresários para integrarem o projeto. Com relação ao conhecimento que os empresários possuem da formação do APL de madeira e móveis de Rondônia foi possível constatar que esse não é um fato conhecido por todos; $35 \%$ dos empresários entrevistados mencionou não saber como o referido APL foi formado.

\subsection{Os agentes Institucionais}

O principal parceiro do APL de madeira e móveis do estado de Rondônia é o Serviço Brasileiro de Apoio às Micro e Pequenas Empresas (SEBRAE). As ações do SEBRAE junto aos APLs começaram em 2000, quando o Sebrae Nacional realizou uma negociação com o Banco Interamericano de Desenvolvimento - BID e com a Câmara de Comércio da Lombardia/Itália - PROMOS no intuito de desenvolver uma experiência piloto de 
desenvolvimento de quatro distritos industriais no Brasil, Nova Friburgo - RJ, Campina Grande - PB, Paragominas - PA e Tobias Barreto - SE. Com o sucesso dessa experiência, em 2002, o SEBRAE estabeleceu como uma de suas prioridades a atuação em Arranjos Produtivos Locais. Em 2003 o Conselho Deliberativo da instituição atualizou o seu planejamento estratégico, tendo definido como uma de suas sete prioridades, para o período 2003-2005, a atuação em ações coletivas, especialmente aquelas focadas nos APLs.

O SEBRAE foi o principal articulador do projeto do APL de madeira e móveis de Rondônia e é o responsável pela coordenação e direcionamento das ações para que se possa atingir os objetivos do arranjo. Existem dois coordenadores do SEBRAE no referido APL João Machado e Roberta Barros, ambos do SEBRAE de Porto Velho. O primeiro trabalha com esse grupo desde o PSI, já a outra coordenadora entrou no projeto quando este migrou para o APL de madeira e móveis de Rondônia. Em 2006, essa coordenação ficou somente a cargo da consultora Roberta Barros.

Há um acordo de resultados elaborado pelo SEBRAE para mostrar formalmente quais as ações os agentes institucionais e econômicos se propuseram realizar até a conclusão do projeto, em dezembro de 2007. Nele foram encontrados outros agentes institucionais participantes do APL de madeira e móveis de Rondônia - Prefeituras dos municípios de Ariquemes, Ji-Paraná, Cacoal, Pimenta Bueno e Rolim de Moura, as Associações Comerciais e Industriais de Ariquemes e Rolim de Moura, a Federação das Indústrias do Estado de Rondônia (FIERO), a Empresa Brasileira de Pesquisa Agropecuária (EMBRAPA), a Secretaria do Estado do Desenvolvimento Ambiental (SEDAM), o Serviço Nacional de Aprendizagem Industrial (SENAI), a Associação de Assistência Técnica e extensão Rural de Rondônia (EMATER), o Banco da Amazônia (BASA), o Centro de Ensino Tecnológico e Negócios de Rondônia (CETENE), a Associação dos Moveleiros Rolimourenses (ASSOM), e a Associação Pimentense de Artefatos de Madeira e Móveis (APPAM).

De acordo com a avaliação dos coordenadores do SEBRAE, a articulação entre os agentes econômicos do arranjo e os demais parceiros do APL de madeira e móveis de Rondônia ainda é fraca e ocasional. Eles informaram que o plano do referido APL de 2005 a 2007 delineia que os parceiros devem atuar de forma contínua tanto na estrutura quanto no apoio financeiro. O que ocorre, no entanto, são apoios pontuais quando solicitados pelo grupo, a exemplo de algumas prefeituras que, quando solicitadas pelos empresários, auxiliam financeiramente para que eles possam custear suas despesas de viagens às feiras nacionais.

Os agentes institucionais que participam de forma mais efetiva é o Governo do Estado 
de Rondônia e a Federação das Indústrias do Estado de Rondônia (FIERO). O primeiro com verbas para as despesas dos empresários nas feiras nacionais em que participam e o segundo com o caminhão que leva as peças para serem expostas nessas feiras.

\subsection{Motivações para integrar ao projeto do $A P L$}

Várias foram as motivações dos empresários para integrar ao projeto do APL objeto do estudo. Verificou-se que a principal delas foi a busca de informações e conhecimentos que os capacitem a melhorar os recursos organizacionais de suas empresas, tais como redução de custos, mudança no design dos produtos, entre outros. Além disso, buscam informações sobre novos produtos e mercados, novos materiais e sobre muitos outros aspectos mercadológicos, que os mantenham atualizados sobre o que está acontecendo no mercado nacional. Algumas razões podem explicar por que existe essa necessidade tão premente por informações e conhecimento. Uma delas é o baixo nível de escolaridade dos empresários, pois a grande maioria não tem formação adequada que possibilite o conhecimento de técnicas gerenciais. Outra razão é a distância desses empresários do mercado que almejam atingir - sul e sudeste do país.

Outra motivação constatada foi a possibilidade de união de forças com outros empresários para a busca da redução dos custos de produção, por meio de compras de matéria prima em conjunto, a possibilidade de aumentar suas vendas, por meio de vendas em conjunto e também a união para a busca de conhecimentos e soluções para problemas enfrentados por todos do setor. Eles já têm consciência de que, sozinhos, a dificuldade para obter maiores vantagens competitivas é maior do que em grupo. A esperança de que conseguirão melhorar suas margens de lucro os motivam a participarem do APL de madeira e móveis de Rondônia.

\subsection{Vantagens percebidas pelos agentes econômicos}

Dentre as vantagens percebidas pelos agentes econômicos para integrar o projeto do APL de madeira e móveis do estado de Rondônia, foram destacadas as que permitiram que os empresários dessem início a uma reestruturação em suas empresas e buscassem inovações em processos e em produtos. Dentro dessa reestruturação da organização foi possível constatar que houve melhorias nas áreas de recursos humanos, com a melhor capacitação dos funcionários da linha de produção; na produção, com maior organização do chão de fábrica e 
melhoria na qualidade dos produtos e na área de finanças, com maior controle dos custos e maior domínio de ferramentas gerenciais.

As feiras nacionais, das quais grande parte dos empresários participou, proporcionaram-lhes a chance de mostrar seus produtos a outros mercados e, desta forma, a chance de comercializar suas peças nos principais mercados nacionais - sul e sudeste - e também alguns mercados internacionais. As informações adquiridas nessas feiras também possibilitaram conhecer tendências em móveis e a alta tecnologia envolvida nas máquinas de produção e em matéria-prima. Desta forma, os empresários puderam trazer novidades e disseminá-las na região. A cooperação entre os empresários também deve ser destacada no rol das vantagens percebidas para as organizações, visto que ao cooperarem uns com os outros, eles perceberam que adquiriram forças para reivindicar junto a outras instituições recursos que beneficiariam a todos. Essa cooperação também gerou outra vantagem: as vendas em conjunto que foram relatadas pelos empresários de Ariquemes.

Além dessas, vale destacar as vantagens pessoais que foram percebidas pelos empresários, a exemplo do crescimento pessoal, do amadurecimento profissional e do incremento dos relacionamentos informais adquiridos no arranjo. A troca de experiências e informações baseada na confiança adquirida entre os integrantes do grupo, além de ajudar com a administração de suas empresas, também proporcionou maior qualificação como gestor. Além disso, o apoio encontrado no parceiro para continuar participando dos cursos, mesmo depois de um dia de trabalho, foi primordial para o aprendizado individual.

\subsection{Desvantagens percebidas pelos agentes econômicos}

A maioria dos empresários não percebeu desvantagens por integrarem o projeto do APL de madeira e móveis de Rondônia Mesmo entre os empresários que não perceberam vantagens, as percepções de fatores negativos foram pontuais e, mesmo assim, não foram tão importantes que os desestimulassem de continuarem no arranjo. Das desvantagens mencionadas, cabe destacar o excessivo tempo despendido em reuniões e projetos, em que nada importante era decidido. Empresários de micro e pequenas empresas são, de forma geral, relutantes em dispor de tempo para freqüentar reuniões que não trarão vantagens imediatas, diferente dos cursos e consultorias, em que eles sentem que o retorno do tempo despendido ocorre mais rapidamente.

Com relação às consultorias realizadas, foi possível perceber que a falta de capital é

REAd - Edição 68, Volume 17, No 1, jan/abr 2011 - p. 237-269 
considerada desvantagem para alguns empresários, pois os impedem de concretizar muitas das ações propostas pelos consultores. Entretanto consideram que o conhecimento adquirido supera essa desvantagem. Eles implantam o que consideram mais urgente e aguardam para realizar as outras melhorias, conforme vão aumentando o capital da empresa.

\subsection{Formas de Cooperação}

As formas de cooperação foram analisadas tanto sob a perspectiva do empresário, como ele coopera com os outros agentes econômicos, quanto sob a perspectiva do principal agente institucional do projeto - o SEBRAE. Foi possível identificar três grupos distintos com níveis diferentes de cooperação. A formação de subgrupos dentro do arranjo se deu por causa das diferentes etapas do arranjo nas quais houve sensibilização de novas empresas para participar do arranjo. O grupo mais antigo, que entrou no início do projeto anterior - o PSI possui laços de cooperação mais fortes. São empresários que estão juntos há mais tempo, além de estarem predispostos a cooperarem uns com os outros desde o início do projeto. Essa continuidade nas relações e predisposição a cooperarem resultam em laços fortes de confiança e intenso fluxo de informações. Esse fluxo de informações os auxiliam muito, pois eles se ajudam a resolver problemas que vão desde o cotidiano da organização, como problemas de produção e com mão-de-obra, até aperfeiçoamento da qualidade e design de produtos.

No grupo intermediário, que entrou com o início do projeto do APL de madeira e móveis de Rondônia, foi possível constatar que as ações voltadas para a cooperação interorganizacional ocorrem pontualmente, sendo um pouco mais freqüentes entre empresários que possuem laços de amizade. Essa cooperação ocorre também com maior freqüência em datas que antecedem as viagens às feiras. Uma explicação para esses laços cooperativos serem mais fracos e ocasionais que o grupo anterior é o fato de estarem dispersos em três cidades diferentes - Ji-Paraná, Cacoal e Pimenta Bueno. Dentre as ações cooperativas cabe destacar as compras pontuais realizadas em conjunto; entretanto tais compras são realizadas somente entre empresários que possuem laços de amizade que antecedem a formação do grupo.

O grupo mais recente, criado há apenas um ano, se localiza em Ariquemes - cidade mais distante dentro do território abrangido pelo projeto do APL de madeira e móveis de Rondônia. Nesse grupo, apesar dos laços de cooperação ainda estarem sendo criados, pode-se perceber que a probabilidade do relacionamento cooperativo se aprofundar é grande, pois já 
estão realizando ações que exigem cooperação, tais como vendas em conjunto.

Finalmente, pode-se concluir que as formas de cooperação mais usuais no APL de madeira e móveis de Rondônia como um todo, são as feiras e empréstimos de pequenos equipamentos e matéria-prima. Na época que antecede as feiras nacionais há uma aproximação entre os empresários dos grupos distintos e uma propensão a se ajudarem mutuamente para que todos possam participar. Essa cooperação vai desde a formação de uma comissão de empresários para buscar verbas junto às instituições parceiras até o rateio das despesas. Pôde-se constatar também a união dos empresários que iriam expor nessas feiras, para montarem um catálogo com as peças de todos. O empréstimo de pequenos equipamentos e matéria-prima é realizada de maneira informal, com base na confiança existente entre empresários que se consideram parceiros.

\subsection{Formas de Governança}

O APL de madeira e móveis do Estado de Rondônia possui uma estrutura de governança central, que é realizada pela instituição que fomentou o arranjo - o SEBRAE. Essa instituição nomeia coordenadores que auxiliam os empresários, primeiramente, a estruturar suas organizações. Eles auxiliam também a criarem uma estrutura de cooperação que possa vir a ser vantajosa para todos. Após essa estruturação, os coordenadores gradativamente passam essa governança para a responsabilidade dos empresários. Além dessa estrutura central, há também as associações nas cidades de Pimenta Bueno e Rolim de Moura que formam uma pequena estrutura de governança nessas cidades. Entretanto foi percebida uma forte dependência na coordenação do Sebrae, para que as ações propostas possam ser concretizadas. Devido a essa dependência e ao desejo dos coordenadores do SEBRAE para que esses empresários se tornem mais independentes, evidenciou-se um conflito no APL de madeira e móveis de Rondônia. Cabe ressaltar que, mesmo no grupo mais antigo, o mais independente no que tange à governança, ainda existe dependência dos coordenadores do Sebrae.

No entanto, esse grupo possui características que podem propiciar essa independência - os empresários se encontram organizados em uma associação forte, há divisão de tarefas nas ações que visam a melhorias para o grupo e possuem laços de cooperação e de confiança. Para os outros dois grupos, a situação é diferente, pois é evidente que ainda não estão maduros para assumirem a coordenação nem mesmo em suas cidades, pois a estrutura de 
cooperação entre os empresários ainda é bastante incipiente.

A maior dificuldade surge quando os coordenadores do SEBRAE assumem que todos os integrantes do APL de madeira e móveis de Rondônia estão no mesmo nível e que todos estão preparados para buscarem a coordenação de seus grupos de forma mais independente. Partindo desse pressuposto, estão deixando de continuar o processo de estruturação dos dois grupos mais recentes do referido APL. Foi possível observar também que os coordenadores do SEBRAE não estão fazendo o acompanhamento das empresas da forma desejada, pois, porquanto estarem localizados na capital, se comunicam por meio de mensagens eletrônicas e telefonemas e, devido a isso, muitas vezes não alcançam os objetivos desejados de informar e acompanhar o desenvolvimento do arranjo.

\subsection{Nível de Formalidade/Informalidade}

De maneira geral, pode-se constatar que os relacionamentos entre os empresários e desses com os agentes institucionais são permeados por ações informais, baseados em laços cooperativos e de confiança. As transações realizadas entre os empresários do APL de madeira e móveis de Rondônia - empréstimos de matéria-prima e pequenas vendas - são feitas sem a utilização de qualquer promissória ou outro papel que formalize o processo. Por serem consideradas sem grandes riscos, os empresários preferem apenas a palavra do parceiro como fonte de garantia do cumprimento da negociação. Outro fato que cabe destacar é a ausência de um contrato entre as empresas que integram o APL de madeira e móveis de Rondônia e a instituição que coordena o arranjo - o SEBRAE. A princípio havia um contrato redigido com uma série de normas que deveriam ser seguidas para a permanência da empresa no arranjo; porém, à medida que as dificuldades iam aumentando, esse contrato foi sendo deixado de lado.

Cabe ressaltar também que existe um relacionamento formal entre as empresas e o Governo do Estado de Rondônia, pois os empresários que desejam a colaboração desse agente institucional devem elaborar um projeto e, após o uso dos recursos, sempre há prestação de contas. Apesar de não haver um estatuto específico do APL de madeira e móveis de Rondônia para guiar a conduta e os relacionamentos dos empresários, há normas estipuladas informalmente em cada grupo participante. São normas criadas no cotidiano dos relacionamentos e são propagadas de um grupo para o outro em eventos sociais, tais como reuniões e viagens.

REAd - Edição 68, Volume 17, No 1, jan/abr 2011 - p. 237-269 


\subsection{Estratégias do APL}

Com relação às estratégias do APL de madeira e móveis de Rondônia, foi constatado que os empresários do grupo 1 (constituído por 09 empresas que participam do grupo há cinco anos), consideram todas as estratégias compatíveis com as de suas organizações. Eles compreendem que, direta ou indiretamente, todos os projetos do referido APL beneficiarão suas empresas. Por sua vez, os integrantes do grupo 2 (constituído por 11 empresas que participam do grupo há dois anos) as conhecem apenas parcialmente e muitos empresários admitem que há projetos que não são compatíveis com as estratégias de suas organizações. $\mathrm{Na}$ percepção deles, muitas estratégias vão além da realidade de algumas organizações, tendo sido elaboradas para empresas que já foram trabalhadas com cursos e consultorias, como as empresas do grupo mais antigo. Finalmente, os empresários do grupo 3 (constituído por 15 empresas, todas localizadas na cidade de Ariquemes, que participam do grupo há um ano) desconhecem totalmente as estratégias elaboradas para o arranjo, até mesmo ações que as beneficiam diretamente, como a consultoria de 5S. Apesar de terem entrado no APL de madeira e móveis de Rondônia quando essas ações já haviam sido delineadas, constatou-se a falha dos coordenadores na transmissão dessas informações, consideradas essenciais para um maior comprometimento.

\subsection{Dificuldades e Sugestões}

Com relação às dificuldades que impedem o APL de madeira e móveis de Rondônia de se desenvolver melhor, de acordo com a percepção dos entrevistados, podem-se destacar no estudo a falta de empenho e participação dos empresários, os problemas com a coordenação do SEBRAE e a cultura individualista em face a uma estrutura de cooperação coletiva. Outro problema mencionado foi com relação à forma de coordenação do SEBRAE, que além de realizar uma coordenação a distância, longe da realidade dos problemas dos empresários, detém o poder de decisão no que tange a escolha de consultores e também com relação ao investimento dos recursos financeiros do APL de madeira e móveis de Rondônia, um dos fatores que impede os empresários de serem mais independentes.

A cultura individualista também foi citada como barreira para o sucesso do APL, porque, sendo um projeto de cooperação coletiva, os empresários que buscam somente REAd - Edição 68, Volume 17, No 1, jan/abr 2011 - p. 237-269 
benefícios particulares colaboram para que o arranjo não se desenvolva. A maior parte dos entrevistados mencionou a participação mais freqüente e empenho dos empresários como fatores chave para o sucesso do projeto.

\section{CONSIDERAÇÕES FINAIS E RECOMENDAÇÕES}

O presente estudo teve como objetivo analisar o arranjo produtivo local (APL) de madeira e móveis do Estado de Rondônia identificando especialmente quais os agentes econômicos e institucionais envolvidos e as suas formas de cooperação e de governança.

Ao se observar os resultados do estudo verficou-se que o APL de madeira e móveis de Rondônia ainda está em fase insipiente com relação a aspectos de governança e cooperação entre os agentes envolvidos. Verificou-se que projetos que visam à colaboração entre as empresas e que possibilitarão vantagens competitivas para as organizações, tais como centrais de compras e construção de estufas para secagem de madeiras, são em sua maioria estruturados para os integrantes de cada subgrupo. Os próprios empresários não se vêem como um grupo coeso que buscam benefícios juntos para as empresas de todas as cidades envolvidas. O único fato que demonstrou colaboração entre os empresários de subgrupos diferentes foi com relação às feiras nas quais eles participam juntos. Entretanto é um fato isolado que não sustenta a idéia do arranjo envolvendo todos como um grupo coeso. Além disso, esses subgrupos se encontram em níveis de desenvolvimento cooperativo e estágios de governança diferentes. Essas diferenças dificultam que ações integradas possam ser tomadas, sendo esse o principal problema para o desenvolvimento do APL de madeira e móveis de Rondônia.

Verificou-se que os empresários já têm consciência de que informação e conhecimento são imprescindíveis para o desenvolvimento de uma organização; porém é necessário compreender que, para buscar o desenvolvimento e a competitividade, a cooperação interorganizacional pode oferecer grande contribuição. Muitas vezes esses empresários tentam solucionar seus problemas sozinhos e se frustram por lutarem e nunca obterem os resultados almejados. A consciência da força coletiva pode gerar resultados positivos para as empresas e proporcionar-lhes a ampliação dos seus horizontes estratégicos.

Esses resultados são coerentes com a visão de Souza e Bacic (2002), quando afirmam que um problema muito comum nesses aglomerados é a inexistência de uma "cultura" e mesmo instituições favoráveis ao desenvolvimento e valorização dos aspectos cooperativos e

REAd - Edição 68, Volume 17, No 1, jan/abr 2011 - p. 237-269 
coletivos entre as pequenas e médias empresas. Ainda afirmam os autores que, a superação de restrições relacionadas à ausência de uma "cultura" que valorize a associação proveitosa entre a vocação empreendedora individual típica das pequenas empresas e as ações coletivas exige disposição, responsabilidade, participação ativa e persistência dos próprios empresários, mas pode ser facilitada pela ativação de um conjunto de medidas que estimulem decididamente essa participação de maneira sustentada.

Sem dúvida, o apoio mútuo entre os empresários pode ajudá-los a encontrar alternativas para os pontos fracos de suas organizações, pois a troca de informações de uma empresa para outra pode propiciar alternativas para solucionar problemas. A troca de experiências nos relacionamentos interorganizacionais proporciona sinergia em torno de uma atividade, gerando resultados para todas as organizações envolvidas. O fato de estarem localizadas em uma mesma região proporciona ainda o compartilhamento de problemas locais e a busca coletiva por apoio de instituições regionais.

Algumas ações de cooperação interorganizacional podem ser utilizadas para desenvolver mais o APL de madeira e móveis de Rondônia, tais como a intensificação do uso compartilhado de infra-estrutura produtiva. Eles podem se beneficiar da compra conjunta de máquinas e equipamentos, softwares, locais de produção e armazenagem, entre outros. Outra ação seria a contratação de consultores, principalmente para os dois grupos mais recentes, para a melhor capacitação das organizações. A criação de centrais de compras, a organização de grupos para produção conjunta de produtos que os possibilitem assumir encomendas maiores e a criação de consórcios para exportação. Por fim, a criação de ações de marketing que beneficiem o arranjo e o território como um todo, valorizando os produtos de madeira da região os tornariam conhecidos nos principais mercados nacionais e internacionais.

No que tange a governança do APL de madeira e móveis de Rondônia, recomenda-se maior presença da coordenação do SEBRAE, por meio de visitas mensais para acompanhar o desenvolvimento e as dificuldades existentes no cotidiano dessas empresas. Os coordenadores deveriam olhar para as empresas do arranjo, não como um bloco uniforme, onde todas se encontram no mesmo nível de desenvolvimento, mas como grupos de necessidades diferentes, tendo projetos diferentes. Trabalhando com subgrupos também há a possibilidade de identificar possíveis líderes e trabalhar junto com eles a formação de uma equipe de coordenação com integrantes dos três grupos do APL de madeira e móveis de Rondônia.

O governo também pode implementar ações que fomentem esse tipo de estrutura interorganizacional no Estado, tais como a criação de novas políticas locais para a promoção 
direta ou indireta das atividades produtivas do arranjo; estímulo a desburocratização, políticas públicas de tributos e incentivos de crédito promovendo a competitividade das empresas do APL de madeira e móveis de Rondônia e implementação de políticas públicas locais/regionais/estaduais que beneficiem o arranjo como um todo, reforçando a convergência e a integração de investimentos públicos, governamentais ou não-governamentais e privados.

\section{REFERÊNCIAS}

AHUJA, G. Collaboration networks, structural holes, and innovation: a longitudinal study. Administrative Science Quarterly, v.45 n. 3, p. 425-455, 2000.

AMATO NETO, J. Redes de cooperação produtiva e clusters regionais: oportunidades para as pequenas e médias empresas. São Paulo: Atlas, 2000.

AMORIM, Mônica Alves. Clusters como Estratégia de Desenvolvimento Industrial no Ceará. Fortaleza: Banco do Nordeste, 1998.

BALESTRIN, A.; VARGAS, L. M. A dimensão estratégica das redes organizacionais de PME: teorizações e evidências. In: Encontro de Estudos em Estratégia, 3Es 1, Curitiba- PR, Anais.... Curitiba: ANPAD, 2003.

BARNIR, A., SMITH, K. An Interfirm alliance in the small business: the role of social networks. Journal of Small Business Management. v. 40, n. 3, p. 219-232, 2002.

BROWN, B., BUTLER, J. E. Competitors as allies: A study of entrepreneurial networks in the U. S. wine industry. Journal of Small Business Management. v.33, n.3, p.57-70,1995.

CASAROTTO FILHO, N., PIRES, L. H.. Redes de pequenas e médias empresas e desenvolvimento local: estratégias para a conquista da competitividade global com base na experiência italiana. 2 ed., São Paulo: Atlas, 2001.

CASTELlS, M.. A sociedade em rede: A era da informação, economia, sociedade e cultura. São Paulo: Paz e Terra, 1999.

COCCO, G.; URANI, A.; PATEZ Galvão, A. Empresários e Empregos nos Novos Territórios Produtivos. O caso da 'Terceira Itália'. Rio de Janeiro: DP\&A, 1999.

CRESWELL, J. Qualitative inquiry and research design: Choosing among five traditions. London: Sage, 1998.

CUNHA, Julio Araujo Carneiro da. Sobre Arranjos Produtivos Locais e Clusters. In: Encontro de Administração Pública e Governança- EnAPG, 3, 2008, Salvador, Anais... Salvador: ANPAD, 2008. 
DYER, J., SINGH, H. The relational view: cooperative strategy and sources of interorganizational competitive advantage. The Academy of Management Review, v. 23, n. 4, 1998, p.660-679.

DOZ, Y. L. The evolution of cooperation in strategic alliances: initial conditions or learning processes? Strategic Management Journal. 17, , p. 55-78, Summer 1996.

GULATI, R. Social structure and alliance formation patterns: a longitudinal analysis. Administrative Science Quarterly, v. 40, n. 4, p. 619-652,1995.

HATCH, M. J. Organization Theory: modern, simbolic and postmodern perspectives. Oxford: Oxford University Press, 1997.

JARILLO, C. On Strategic Networks. Strategic Management Journal. v. 9, n. 1, p. 31-4, 1988.

KUSHIMA, Alzira; BULGACOV, Sergio. Estratégias e Relações em Arranjos Produtivos e seus Efeitos sobre Cadeias de Valores: o Consórcio de Maringá e o Projeto Setorial Integrado de Apucarana. Revista Organizações \& Sociedade, v. 13, n. 37, 2006.

JONES, C.; HESTERLY, W. S., BORGATTI, S. P. A general theory of network governance: Exchange conditions and social mechanisms. The Academy of Management Review, v. 22, n. 4, p. 911-925, 1997.

LASTRES, Helena M. M e CASSIOLATO, José Eduardo. . Novas Políticas na Era do Conhecimento: $O$ foco em Arranjos produtivos e Inovativos Locais. Disponível em: http://www.redesist.ie.ufrj.br/nt_count.php?projeto=ar1\&cod=2. Acesso em: 26/01/2010.

LASTRES, H. M. M e CASSIOLATO, J. E;. Glossário de Arranjos de Sistemas Produtivos e Inovativos Locais: Uma nova estratégia de ação para o Sebrae. Rede de Pesquisa em Sistemas Inovativos Locais - RedeSist, 2005.

LECHNER; Christian; DOWLING, Michael.Firm networks: external relationships as sources for the growth and competitiveness of entrepreneurial firms. Entrepreneurship \& Regional Development, v. 15, p. 1-26, 2003.

LOPES, F. D.; BALDI, M. Laços sociais e formação de arranjos organizacionais cooperativos - Proposição de um modelo de análise. Revista de Administração Contemporânea, v. 9, n. 2, p. 81-101, 2005.

LOPES, H. G.; MORAES, F. R. Redes e organizações: algumas questões conceituais e analíticas. In: Encontro de Estudos Organizacionais-ENEO, Curitiba-PR, 2000, 1. Anais... Curitiba:ANPAD, 2000.

MARIA, A. S. R. I.; FARIA; V. C. M. e AMORIM, M. A. A Comunidade de Prática da Rede Nós: Colaborando e Compartilhando Conhecimentos em Arranjos Produtivos Locais.

Organizações \& Sociedade, v.15 - n.44 -p.149-170, Jan./Mar, 2008.

MILES, R. E.; SNOW, C. C. Network organizations: new concepts for new forms. California Management Review. California, v. 23, n. 3, p. 62-73, spring 1986.

REAd - Edição 68, Volume 17, No 1, jan/abr 2011 - p. 237-269 
MILES, R. E.; SNOW, C. C. Causes of Failure in Network Organizations. California Management Review, v. 34, n. 4, p 53- 71,1992.

OLIVEIRA JUNIOR, Z. G. de; CASTRO, D. S. P. de. Gestão do Conhecimento em Arranjos Produtivos Locais Estudo de Caso do Pólo Brasileiro de Cosmético em Diadema. In:

Encontro da Associação Nacional de Programas de Pós-Graduação em Administração-

ENANPAD, 32, 2008. Rio de Janeiro. Anais... Rio de Janeiro: ANPAD, 2008.

OLIVER, C. Determinants of Interorganizational Relationships: Integration and Future Directions. The Academy of Management Review. v. 15, n. 2, p. 241-265, 1990.

OLIVER, A L.; EBERS, M. Networking Network Studies: an analysis of conceptual configurations in the study of interorganizational relationships. Organization Studies. Fall, 1998.

PAIVA JR., F. G.; BARBOSA, F. V. Redes Organizacionais no Sistema de Cluster: reflexões sobre sua posição estratégica na busca de oportunidades pelas pequenas e médias empresas. In: Encontro Nacional de Pós Graduação em Administração- ENANPAD, 25, Campinas- SP, 2001, Anais....Campinas: ANPAD, 2001.

PIORE, M. J.; SABEL, C. F. The Second Industrial Divide. New York: Basic Books; 1984. PORTER, M. E. Competição: estratégias competitivas essenciais. 10 ed. Rio de Janeiro: Campus, 1999.

PORTER, Michael E. Clusters and the new economics of competition. Harvard Business Review, v. 76, n. 6, p. 77-90, nov/dec. 1998.

RING, P. S.; VAN DE VEN, A. H. Structuring Cooperative Relationships between Organizations. Strategic Management Journal, v.13, n.7, 1992, p. 483-498.

ROSA, A. V. A. Análise do arranjo produtivo local como estratégia competitiva de pequenas empresas de transporte rodoviário de cargas: o caso do Grupo Oeste Transportes de Oswaldo Cruz - SP. 2004, 135 f. Dissertação (Mestrado em Administração)- Pontifícia Universidade Católica do Paraná, Curitiba, Paraná, 2004.

SAMPAIO, C. A. C. LEÓN, I. C. de; DALLABRIDA, I. S.; PELLIN, V. Arranjos

Socioprodutivos de Base Comunitária: Arranjos Produtivos Locais pensados como arranjos institucionais. o caso da Mondragón corporação cooperativa. Organizações \& Sociedade, v.15 - n.46 ,p.77-98, julho-setembro, 2008.

SCHEFFER, J.; CARIO, S. A. F. NICOLAU, J. A. Capacitação Tecnológica de Micro e Pequenas Empresas em Arranjos Produtivos Locais: um Estudo no Segmento de Materiais Plásticos. RAC-Eletrônica, v. 2, n. 1, p. 20-36, 2008.

SCHMITZ, H. Collective efficiency: growth path for small scale industry. The Journal of Development Studies, v. 31, n .4, p. 529-566, 1995.

SILVA, L. H. R. da; CARDOSO, F. dos S.; MONTEIRO, M. G.. Analisando os Arranjos Produtivos Locais sob a Perspectiva de Gilberto Freyre e Roberto Da Matta: A Dualidade 
entre a Casa e a Rua. In: Encontro de Administração Pública e Governança, EnAPG,.1, 2006, São Paulo. Anais.... São Paulo: ANPAD, 2006.

SONAGLIO, C. M., MARION FILHO, P. J. A Inovação Tecnológica em Arranjos Produtivos Locais: a Indústria de Móveis Retilíneos Residenciais de Bento Gonçalves (RS). In: Simpósio da Gestão da Inovação Tecnológica, 25, 2006, Gramado, RS. Anais....Rio de Janeiro: ANPAD, 2006.

SOUZA, M. C. A. F. de; BACIC; M. J. Restrições ao Desenvolvimento de Alianças e Práticas Inovadoras em Arranjos Produtivos Locais: O Caso do Setor de Plásticos do ABC Paulista. In: Encontro Nacional de Pós Graduação em Administração, ENANPAD-26, Salvador, BA, 2002, Anais....Rio de Janeiro: ANPAD, 2002.

SOUZA, M. C. de A. F. e MAZZALI, L. Conceito e espaço da pequena empresa na estrutura industrial: heterogeneidade e formas de inserção. Gestão \& Produção, v. 15,n. 3. p. 591-603, set-dez-. 2008.

SUZIGAN, W.; FURTADO, J; GARCIA, R. \& SAMPAIO, S. Clusters ou sistemas locais de produção: mapeamento, tipologia e sugestões de política. Revista de Economia Política, vol. 24 n. 4, 2004, p. 35-60.

TEIXEIRA, F.- Políticas Públicas para o Desenvolvimento Regional e Local: O que Podemos Aprender com os Arranjos Produtivos Locais (Apls)? Organizações e Sociedade, v.15 - n.46 - Jul/Set., 2008.

VALE, G. M. V. Aglomerações Produtivas e Estudos Organizacionais: em Busca de uma Tipologia sobre Novas Conformações Organizacionais. In: Encontro da Associação Nacional de Programas de Pós-Graduação em Administração, ENANPAD, 31, 2007. Rio de Janeiro. Anais... Rio de Janeiro: ANPAD, 2007.

WILLIAMSON, O. E. The Economics of Organization: The Transaction Cost Approach. The American Journal of Sociology, v. 87 n. 3, p. 548-577, 1981.

WILLIAMSON, O. E. Transaction-cost economics: the governance of contractual relations. Journal of Law and Economics, 22, 1979; p. 35-60.

YIN, R. K. Estudo de caso: planejamento e métodos . 2. ed. Porto Alegre: Bookman; 2001.

\section{RESUMO}

Este estudo tem por objetivo identificar os agentes econômicos e institucionais do arranjo produtivo local (APL) de madeira e móveis do Estado de Rondônia e analisar suas formas de relacionamento, cooperação e governança. Foram utilizados os procedimentos metodológicos relativos ao estudo de caso, com a adoção de uma perspectiva de análise transversal. O nível de análise considerado foi o APL e a unidade de análise foram os gestores tanto das empresas quando das instituições envolvidas. A população abrangida na pesquisa somou trinta e cinco organizações integrantes do arranjo produtivo local de madeira e móveis de Rondônia, das quais vinte e quatro foram visitadas e seus dirigentes, entrevistados. Para a realização da pesquisa, foram utilizados dados primários, coletados por meio de entrevistas semiestruturadas e observação direta não-participante do pesquisador, além de dados secundários. Os resultados levam a concluir que o APL de madeira e móveis do Estado de Rondônia ainda REAd - Edição 68, Volume 17, No 1, jan/abr 2011 - p. 237-269 
não existe como um arranjo propriamente dito, mas sim como três subgrupos com estágios diferentes em seus laços de cooperação. A colaboração foi percebida dentro de um dos subgrupos, tornando as empresas participantes mais bem preparadas e capacitadas. Portanto, o desafio é entender esse APL com necessidades e capacidades diferentes, onde as empresas se encontram em diferentes estágios de desenvolvimento.

Palavras-chave: Arranjo produtivo local, rede interorganizacional, relacionamentos organizacionais, cooperação, governança.

\title{
RELATIONS, COOPERATION AND GOVERNANCE IN LOCAL PRODUCTION ARRANGEMENTS: THE CASE OF APL WOODEN FURNITURE AND STATE RONDÔNIA
}

\begin{abstract}
This research had as objective to identify economic and institutional agents of Rondônia wood and furniture cluster and analyze its relationship, cooperation and governance. The methodological approach were the case study, with the adoption of a perspective of transversal analysis. The analysis level was the cluster and the analysis unit were the cluster and institutional management. The population was of thirty-five participant organizations of the wood and furniture cluster of Rondônia and, from those, twenty-four were visited and their managers interviewed. For the accomplishment of the research, sources of primary and secondary data were used, semi-structured interviews and non-participant observation were adopted. Results conclude that the wood and furniture cluster of Rondônia does not exist as a cluster yet, but as three sub-groups in different stages in their cooperation ties. Collaboration was perceived in one of the three sub-groups, making the companies more prepared and skilled. Thereby, the main challenge is understand this cluster with different necessities and capabilities where organizations are in the different levels of development
\end{abstract}

Keywords: Cluster, inter-organizational network, organization relationships, cooperation, governance. 